Postprint: Janssen H. 2020. A critique "A cell model of effective thermal conductivity for saturated porous media", International Journal of Heat and Mass Transfer, 176:121320.

doi: 10.1016/j.jheatmasstransfer.2021.121320

\title{
A CRITIQUE ON “A CELL MODEL OF EFFECTIVE THER- MAL CONDUCTIVITY FOR SATURATED POROUS MEDIA"
}

HANS JANSSEN ${ }^{\mathrm{a}, *}$

a: KU Leuven, Department of Civil Engineering, Building Physics \& Sustainable Design

*: corresponding author, Kasteelpark Arenberg 40, 3001 Leuven, Belgium;

hans.janssen@kuleuven.be; +32 16321326

\begin{abstract}
In August 2019, this journal published the paper "A cell model of effective thermal conductivity for saturated porous media" (Zhu, 2019), which develops and validates a new analytical prediction model for the thermal conductivities of saturated porous materials. This critique reveals that the model is conceptually and practically flawed, by on the one hand showing that it may result in thermal conductivities outside of the series and parallel limits and by on the other hand exposing its poor performance for dry porous media contrary to Zhu's positive outcomes. Given that these flaws, if known to the author and/or reviewers, would (probably) have led them to a "not fit for publication" evaluation, the discusser suggests an official retraction of (Zhu, 2019).
\end{abstract}

\section{KEYWORDS}

Effective thermal conductivity; Porous media; Cell model; Series and parallel limits; Air thermal conductivity; Retraction 
Postprint: Janssen H. 2020. A critique "A cell model of effective thermal conductivity for saturated porous media", International Journal of Heat and Mass Transfer, 176:121320.

\section{INTRODUCTION}

doi: 10.1016/j.ijheatmasstransfer.2021.121320

In August 2019, this journal published the paper "A cell model of effective thermal conductivity for saturated porous media" (Zhu, 2019), which develops and validates a new analytical prediction model for the thermal conductivity of saturated porous materials. A detailed analysis by the discusser reveals that the model is both conceptually and practically flawed. This critique firstly establishes that the model may yield thermal conductivities outside of the bounds defined by the series and parallel and the Hashin \& Shtrikman limits. The critique secondly demonstrates that the model does actually not perform well for dry materials, contrary to Zhu's positive findings for these configurations. The critique finally suggests to have the paper retracted from the journal, given the publisher's adherence to the policies of the Committee on Publication Ethics (COPE), and the conjecture that neither author nor reviewers would probably have deemed it fit for publication, should they have been aware of the conceptual and practical failure of the model.

\section{DESCRIPTION OF ZHU'S (2019) MODEL}

Zhu first abstracts the saturated porous medium towards a collection of spherical solid particles immersed in a fluid and then boils this further down to a single cell consisting of a spherical solid core enclosed by a spherical fluid shell. Figure 1 (left) illustrates that concept: the black sphere represents the solid particle and the red sphere the surrounding fluid. The total heat conduction through the porous medium is assumed equivalent to that through this unit cell. A temperature gradient is imposed over the cell, and the temperature distributions and heat flows in the cell are solved analytically. These heat flows are finally translated to the equivalent thermal conductivity of the porous medium based on the effective medium idea, resulting in this equation:

$$
\mathrm{k}_{\mathrm{e}}=\mathrm{k}_{\mathrm{f}} \frac{3 \mathrm{k}_{\mathrm{s}} / \mathrm{k}_{\mathrm{f}}-2\left(\mathrm{k}_{\mathrm{s}} / \mathrm{k}_{\mathrm{f}}-1\right)[\phi+(1-\phi) \ln (1-\phi)]}{3+\phi\left(\mathrm{k}_{\mathrm{s}} / \mathrm{k}_{\mathrm{f}}-1\right)}
$$

with $\mathrm{k}_{\mathrm{f}}, \mathrm{k}_{\mathrm{s}}, \mathrm{k}_{\mathrm{e}}[\mathrm{W} / \mathrm{mK}]$ thermal conductivity of the fluid, thermal conductivity of the solid and equivalent thermal conductivity of the saturated porous medium respectively, and $\phi[-]$ the porosity. An illustration of the predictions made with the model are shown in Figure 1 (right), which shows that the model basically gives results similar to these of already existing models.
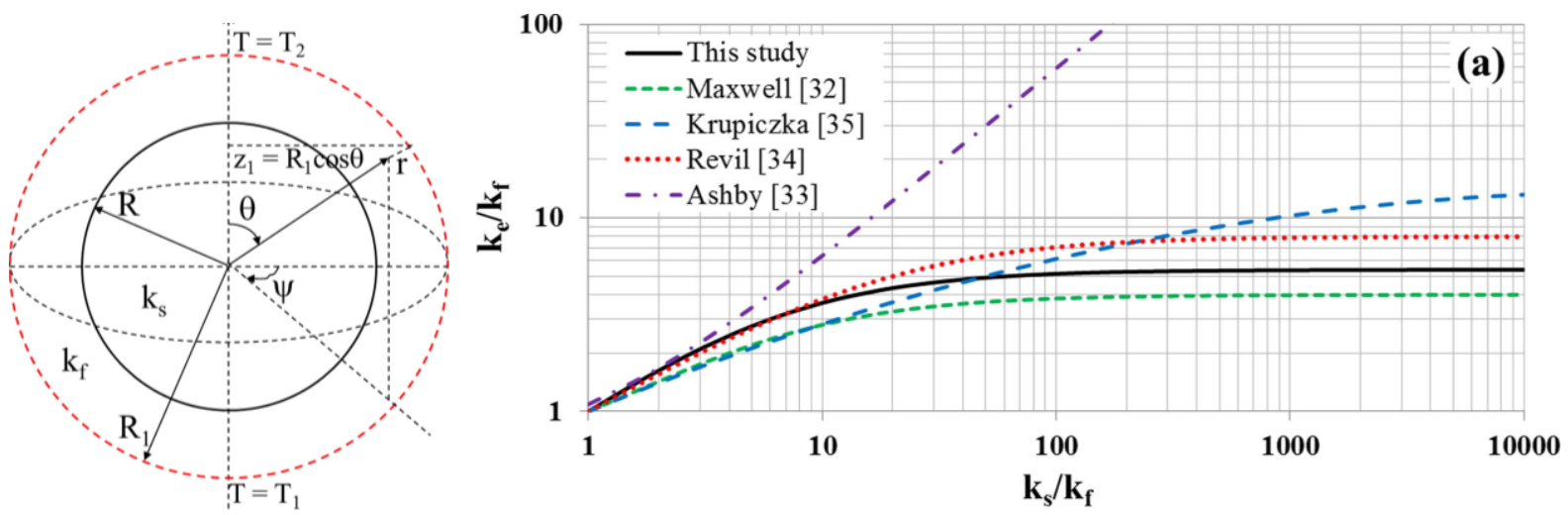

Figure 1: basic concept of Zhu's model for thermal conductivity prediction (left) and comparison of cell model predictions to other models (right); adopted from (Zhu, 2019)

\section{Conceptual failure of Zhu's model}

Figure 2 confronts the outcomes of Zhu's model to the bounds defined by the series and parallel and the Hashin \& Shtrikman limits (Carson et al., 2005). For the top graph $\mathrm{k}_{\mathrm{f}}$ and $\mathrm{k}_{\mathrm{s}}$ are equal to $0.0285 \mathrm{~W} / \mathrm{mK}$ and $7.2 \mathrm{~W} / \mathrm{mK}$, for the center graph to $0.59 \mathrm{~W} / \mathrm{mK}$ and $7.2 \mathrm{~W} / \mathrm{mK}$, for the bottom graph to $3.6 \mathrm{~W} / \mathrm{mK}$ and $7.2 \mathrm{~W} / \mathrm{mK}$. The $0.0285 \mathrm{~W} / \mathrm{mK}, 0.59 \mathrm{~W} / \mathrm{mK}, 7.2 \mathrm{~W} / \mathrm{mK}$ respectively relate to air, brine or water, quartz; more on these in the next section. The $3.6 \mathrm{~W} / \mathrm{mK}$ does not readily relate to a real fluid, it is just selected to make a point; more on that further below in this section. The top graph $(0.0285 \& 7.2)$ illustrates that, for relatively weakly conducting fluids, Zhu's model 
Postprint: Janssen H. 2020. A critique "A cell model of effective thermal conductivity for saturated porous media", International Journal of Heat and Mass Transfer, 176:121320.

doi: 10.1016/j.ijheatmasstransfer.2021.121320

leans strongly to the series limit, considering the medium as a series of layers of the composing materials, and hence differs highly from the parallel limit, viewing the porous medium as a set of
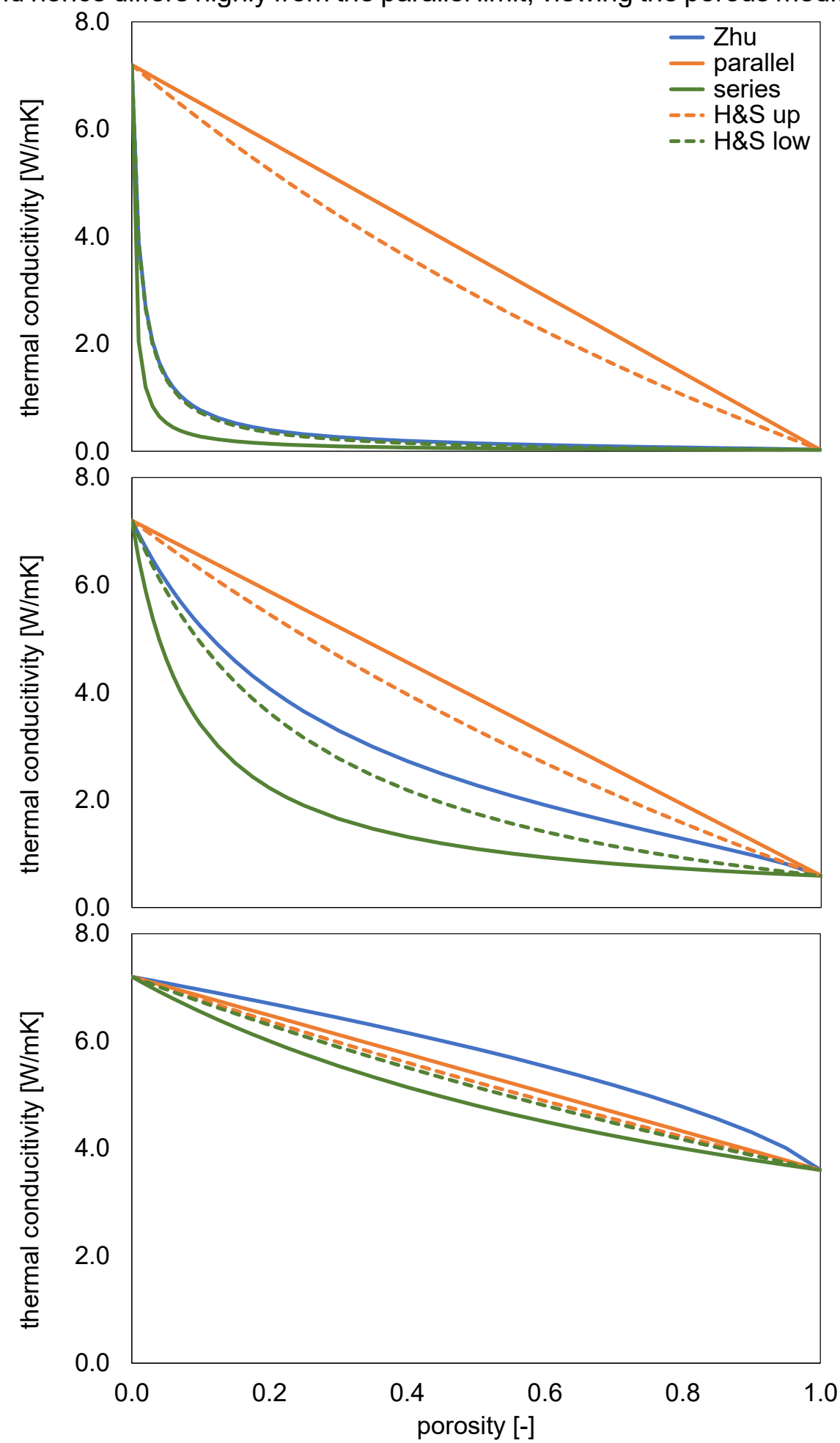

Figure 2: confrontation of Zhu's model predictions with the parallel and serial and the Hashin and Shtrikman bounds for $k_{f} 0.0285 \mathrm{~W} / \mathrm{mK} \& k_{s} 7.2 \mathrm{~W} / \mathrm{mK}$ (top), $k_{f} 0.59 \mathrm{~W} / \mathrm{mK} \& k_{s} 7.2 \mathrm{~W} / \mathrm{mK}$ (centre), $k_{f} 3.6 \mathrm{~W} / \mathrm{mK} \& k_{s} 7.2 \mathrm{~W} / \mathrm{mK}$ (bottom)

parallel columns of the composing materials. This is of course evident, given the basic concept of Zhu's cell, see Figure 1 (left). The solid particle is fully surrounded by the fluid shell, and therefore no continuous column of solid material exists. The heat transfer through the cell is hence determined by the series of the fluid layer above the solid particle, the mixture of fluid and solid 
Postprint: Janssen H. 2020. A critique "A cell model of effective thermal conductivity for saturated porous media", International Journal of Heat and Mass Transfer, 176:121320.

doi: 10.1016/j.ijheatmasstransfer.2021.121320

in the centre part, the fluid layer below the solid particle. And with a relatively weakly conducting fluid, the top and bottom fluid layers dominate the resistance, and thus the conductivity, of Zhu's cell. This structure is very similar to the configuration considered for the lower Hashin \& Shtrikman limit, and it can be seen that Zhu's model closely matches that limit, see Figure 2 (top). The centre graph $(0.59 \& 7.2)$ reveals that, for relatively better conducting fluids, Zhu's model shifts somewhat to the average of the series and parallel limits, which can also be explained based on the basic concept of Zhu's cell, see Figure 1 (left). For such configuration with a relatively better conducting fluid, the resistance of the mixed centre part starts playing a more weighty role, thus shifting the thermal conductivity somewhat upward, toward the parallel limit. The bottom graph (3.6 \& 7.2) does however reveal that Zhu's model takes this shift too far, as it produces thermal conductivities above the parallel limit for fluid conductivities slightly below the solid conductivity. It can equally be shown that Zhu's model produces conductivities below the series limit for fluid conductivities slightly above the solid conductivity. This demonstrates that Zhu's cell model for the thermal conductivity of saturated porous materials is conceptually flawed, given that no such model should be allowed to produce thermal conductivity estimates outside of the series and parallel and/or Hashin \& Shtrikman limits. Unfortunately, the discusser cannot come to a plausible explanation for this behaviour, and hopes that the author can address this in his response.

\section{Practical failuRe of Zhu's MOdel}

Besides the conceptual failure of Zhu's model for configurations with not too different conductivities for fluid and solid, Zhu's model actually also fails practically for configurations wherein the fluid conductivity is much lower than the solid conductivity. In (Zhu, 2019), a good agreement of calculations and experiments is demonstrated, with data for quartz sands and sandstones saturated with brine or air. Unfortunately, the good agreement for the air-saturated (dry) materials is a result of Zhu's use of erroneous air conductivities, as revealed below.

Introductorily though, the good agreement for the brine-saturated materials is briefly discussed. In his Figure 3, Zhu confronts calculations to experiments for quartz sands saturated with brine, for which he assumes conductivities of $7.2 \mathrm{~W} / \mathrm{mK}$ and $0.59 \mathrm{~W} / \mathrm{mK}$ respectively. The experimental data are taken from Somerton (1992), Brigaud and Vasseur (1989), Zamorra et al. (1993). It should be noted that only Somerton (1992) used quartz sands and brine, Brigaud and Vasseur (1989) and Zamorra et al. (1993) actually employed sandstones (albeit very rich in quartz) and water. All of these furthermore in fact put forward $7.7 \mathrm{~W} / \mathrm{mK}$ as quartz's thermal conductivity. It appears hence that Zhu (2019) has misrepresented his sources to some extent, albeit with only minor impact, as Zhu's Figure 3 depicts a decent match between calculations and experiments. In his Figure 4, Zhu gets a slightly worse agreement for Somerton's (1992) oil sands and brine, but all in all, it can be concluded that the Zhu's cell model appears adequate for saturated porous media wherein the fluid conductivity is not very much below the solid conductivity.

A different story unfolds however for saturated porous media wherein the thermal conductivity of the fluid is much lower than that of the solid, in this case quartz sands and sandstones saturated with air (dry). Zhu appears to confirm the satisfactory performance of his model for these configurations in his Figures 4 and 5, where he confronts his calculations with experiments (both real and virtual) on oil sands, by Somerton (1992) in Figure 4 and by Askari et al. (2015) in Figure 5. For Figure 4, Zhu applies a thermal conductivity of $0.055 \mathrm{~W} / \mathrm{mK}$ for air, for Figure 5 he reports a thermal conductivity of $0.0262 \mathrm{~W} / \mathrm{mK}$ for air. It is peculiar that Zhu puts forward these two highly different values, but the bigger issues are that the former is not a credible value for air and that the latter does not allow reproducing Zhu's results.

Figure 3 (top) confronts calculations via Zhu's model to experiments by Somerton (1992) on quartz sands saturated with air. Somerton (1992) clearly reports a value of $0.0285 \mathrm{~W} / \mathrm{mK}$ for air, see his Figure V-21, but Figure 3 (top) shows a manifest deviation between calculations and experiments for this value, whereas a decent agreement is only achieved with $0.055 \mathrm{~W} / \mathrm{mK}$ for air. At atmospheric pressure, such value relates to temperatures of about $500^{\circ} \mathrm{C}$, much higher than the roughly $100^{\circ} \mathrm{C}$ at which Somerton (1992) performed his experiments. The discusser cannot determine where the value of $0.055 \mathrm{~W} / \mathrm{mK}$ stems from, but can only observe that this choice has contributed to an erroneously positive evaluation of Zhu's model for dry materials. 
Postprint: Janssen H. 2020. A critique "A cell model of effective thermal conductivity for saturated porous media", International Journal of Heat and Mass Transfer, 176:121320.

doi: 10.1016/j.ijheatmasstransfer.2021.121320

The performance of Zhu's model further deteriorates when considering the sandstones of (Brigaud and Vasseur, 1989; Zamorra et al., 1989) saturated with air. For reasons unknown to the discusser, Zhu does not include these data, despite them being readily available. In Figure 4 (centre), calculations with Zhu's model are confronted with experiments on the sandstones. It is
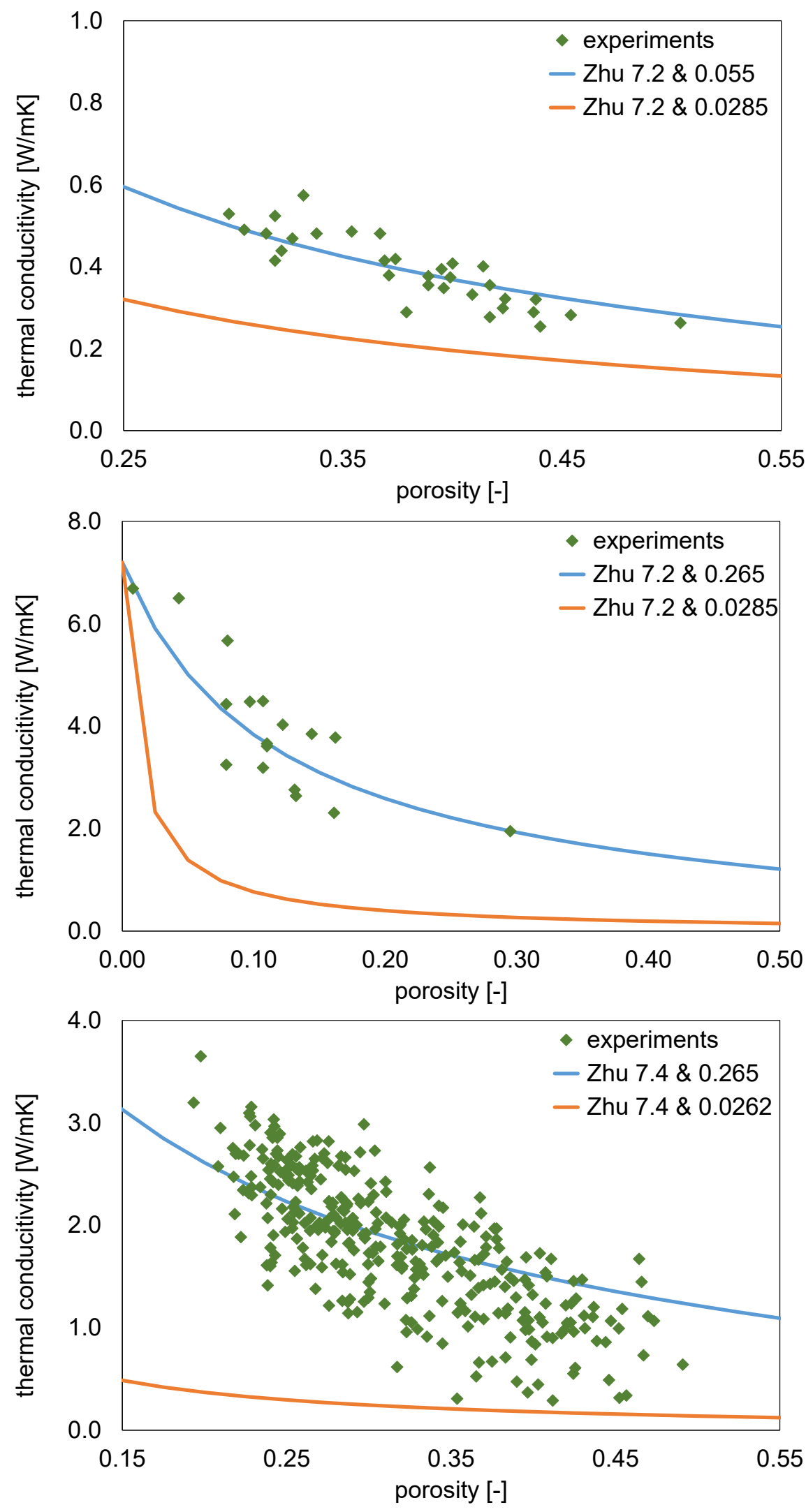
Postprint: Janssen H. 2020. A critique "A cell model of effective thermal conductivity for saturated porous media", International Journal of Heat and Mass Transfer, 176:121320.

doi: 10.1016/j.ijheatmasstransfer.2021.121320

Figure 3: confrontation of Zhu model calculations to experiments: quartz sands and air (Somerton, 1992) (top), sandstones and air (Brigaud \& Vasseur, 1989; Zamorra et al., 1993)

(centre), oil sands and air (Askari et al., 2015) (bottom).

clear that calculations with $0.0285 \mathrm{~W} / \mathrm{mK}$ for air greatly underestimate the experiments. Instead, it can be determined that a value of about $0.265 \mathrm{~W} / \mathrm{mK}$ for air is required to get a good agreement, see again Figure 4 (centre). Such high value for the thermal conductivity of air is however not realistic: at atmospheric pressure, such value only occurs at temperatures over $2000^{\circ} \mathrm{C}$. The critical reason for Zhu's model underestimating the measured thermal conductivities of porous media saturated with air - or alternatively requiring (far) higher thermal conductivities of air to achieve a good agreement with experiments - is evident. In such configurations, the contacts between the strongly conductive solid particles play a substantial role in the overall heat conduction, whereas Zhu's model inherently postulates that no such particle contacts exist, see Figure 1 (left). This also explains the values of $0.055 \mathrm{~W} / \mathrm{mK}$ versus $0.265 \mathrm{~W} / \mathrm{mK}$ required to get good agreements for quartz sands versus sandstones. The loose particle contacts for the non-cohesive quartz sands remain small relative to the cemented particle contacts for the cohesive sandstones. In Zhu's model, the impact of these weak and strong particle contacts can only be compensated via weak and strong overvaluations of the air thermal conductivity.

In light of the argumentation above, it is peculiar that Zhu obtains a decent agreement between the calculations and experiments for the Utah oil sands of (Askari et al., 2015), see his Figure 5, supposedly with a thermal conductivity of $7.4 \mathrm{~W} / \mathrm{mK}$ for quartz and of $0.0262 \mathrm{~W} / \mathrm{mK}$ for air. The latter cannot be correct however, as calculations by the discusser in Figure 3 (bottom) reveal a strong disagreement between calculations and experiments for this value. The good agreement reported by Zhu can only be obtained when imposing roughly $0.265 \mathrm{~W} / \mathrm{mK}$ for air. This finding is confirmed in Figure 4, overlaying the discusser's calculations with Zhu's Figure 4. It is evident that using the mentioned $0.0262 \mathrm{~W} / \mathrm{mK}$ for air does not agree with Zhu's curves: the $\mathrm{k}_{\mathrm{e}} / \mathrm{k}_{\mathrm{f}}$ values obtained by the discusser are substantially higher. Only when employing $0.265 \mathrm{~W} / \mathrm{mK}$ for air can Zhu's curves for his and Maxwell's model be reproduced.

The analysis above has demonstrated that Zhu's cell model, while giving satisfactory results for saturated porous media wherein the fluid is not very much less conductive than the solid, performs very poorly for porous media wherein the fluid is much less conductive than the solid, in casu the quartz sands and sandstones saturated with air. The cause for such poor performance for these configurations is clear: Zhu's cell model, with a solid particle wholly enclosed by a fluid shell, simply cannot consider the impact of the solid particle contacts. These contacts however have a strong effect for such configurations, as they provide a weak or strong (depending on the nature of the contacts) continuous path through the more conductive solid material. Besides the conceptual failure brought up in the preceding section, Zhu's model hence obviously also suffers from a practical failure, as it cannot reliably quantify the thermal conductivity of porous materials with fluid conductivity much lower than solid conductivity. 
Postprint: Janssen H. 2020. A critique "A cell model of effective thermal conductivity for saturated porous media", International Journal of Heat and Mass Transfer, 176:121320.

doi: $10.1016 /$ j.ijheatmasstransfer.2021.121320

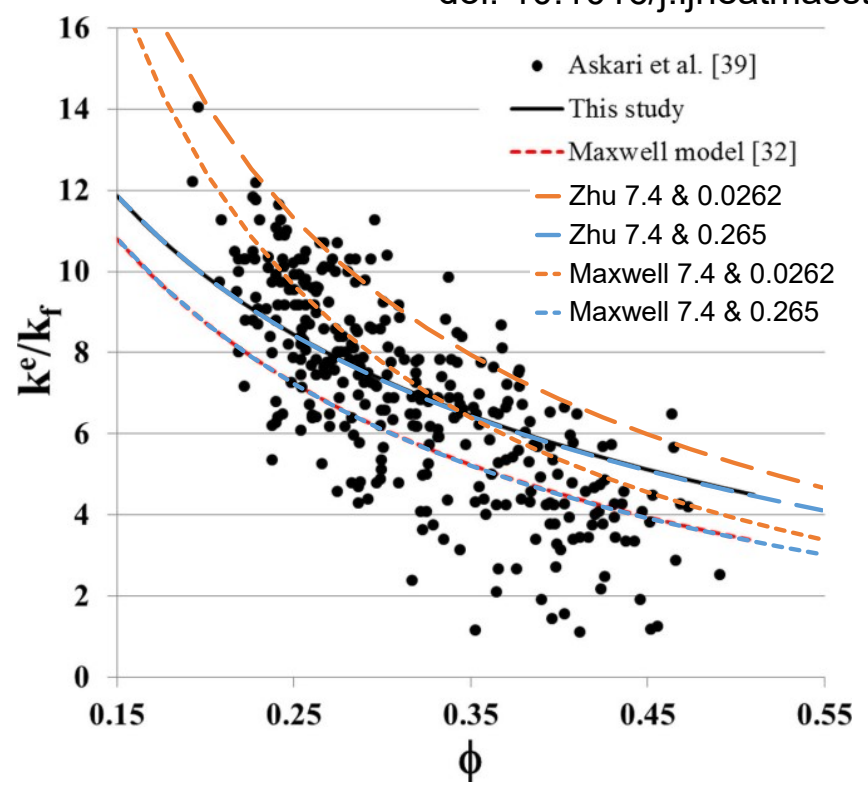

Figure 4: confrontation of Zhu and Maxwell model predictions as presented in (Zhu, 2019) and calculations by the discusser

\section{Conclusions}

In August 2019, this journal published the paper "A cell model of effective thermal conductivity for saturated porous media" (Zhu, 2019), which develops and validates a new analytical prediction model for the thermal conductivities of saturated porous materials. This critique reveals that the model is conceptually and practically flawed, by on the one hand showing that it may result in thermal conductivities outside of the series and parallel limits and by on the other hand exposing its poor performance for dry porous media contrary to Zhu's positive outcomes. Zhu's model is hence undependable, and should therefore best be shunned. Sadly, the author has already built upon this model in two ensuing publications (Zhu, 2020a, 2020b): as both are based on a faulty model, they should best be similarly ignored.

Given the flaws revealed in this critique, the discusser strongly doubts whether the author and/or reviewers of Zhu (2019) would have deemed the Zhu model and article fit for publication, should they have been aware of the demonstrated conceptual and practical failure. For that reason the discusser suggests to have the article (Zhu, 2019) retracted from the journal; such retraction will also prevent confusion for future readers. This suggestion for retraction is in line with the COPE (Committee on Publication Ethics) guidelines on retraction (COPE, 2019): these guidelines unambiguously say that "editors should consider retracting a publication if they have clear evidence that the findings are unreliable". In the opinion of its author, this critique has clearly established that the findings in Zhu (2019) are unreliable.

\section{CONFLICTS OF INTEREST}

The author declares that he have no conflict of interest.

\section{ACKNOWLEDGMENTS}

This research was in part supported by the FWO Odysseus grant (G.0C55.13 N), which is gratefully acknowledged.

\section{REFERENCES}

Askari R, Taheri S, Hejazi SH, 2015. Thermal conductivity of granular porous media: a pore scale modeling approach. AIP Advances 5:097106. 
Postprint: Janssen H. 2020. A critique "A cell model of effective thermal conductivity for saturated porous media", International Journal of Heat and Mass Transfer, 176:121320.

doi: 10.1016/j.jheatmasstransfer.2021.121320

Brigaud F, Vasseur G, 1989. Mineralogy, porosity and fluid control on thermal conductivity of sedimentary rocks. Geophysical Journal 98:525-542.

COPE, 2019. Committee of Publication Ethics' Retraction guidelines. Retrieved online at March 2 2021, at https://publicationethics.org/retraction-guidelines.

Carson JK, Lovatt SJ, Tanner DJ, Cleland AC, 2005. Thermal conductivity bounds for isotropic, porous materials. International Journal of Heat and Mass Transfer 48:2150-2158.

Somerton WH, 1992. Thermal properties and temperature-related behavior of rock/fluid systems, Elsevier Science, New York, United States.

Zhu J, 2019. A cell model of effective thermal conductivity for saturated porous media. International Journal of Heat and Mass Transfer 138:1054-1060.

Zhu J, 2020a. Unsaturated cell model of effective thermal conductivity of soils. SN Applied Sciences 2:1395.

Zhu J, 2020b. Impact of size distribution of cell model on the effective thermal conductivity of saturated porous media. International Journal of Thermophysics 41:34.

Zamora M, Vo-Thanh D, Bienfait G, Poirier J-P, 1993. An empirical relationship between thermal conductivity and elastic wave velocities in sandstone. Geophysical Research Letters 20:16791682. 